\title{
El CARÁCTER PROBLEMÁTICO Y AUTO-PROBLEMÁTICO DEL INDIVIDUO SEGÚN SIMONDON ${ }^{1}$ The Problematic and Self-problematic Nature of the Individual
According to Simondon
}

\author{
Juan Manuel Heredia ${ }^{2}$
}

DOI: 10.17533/udea.rp.v10n1a02

Recibido: 2017-10-01 Aceptado: 2017-12-21

Para citar este artículo en APA: Heredia, J. (2018). El carácter problemático y auto-problemático del individuo según Simondon. Revista de Psicología Universidad de Antioquia, 10 (1),

45-68. DOI: 10.17533/udea.rp.v10n1a02

Resumen: En este trabajo se analiza el concepto de subjetividad individual en la teoría de la individuación de Gilbert Simondon desde un triple horizonte. Por un lado, se reconstruyen los rasgos principales de la individualidad biológica y se aborda la diferencia de grado entre lo vital y lo psíquico. Por otro lado, se argumenta que dicha diferencia se explica en función de una reconfiguración del régimen afectivo y cognitivo, se establece el carácter problemático y auto-problemático del individuo y se analizan una serie de elementos psicogenéticos relacionando la teoría simondoniana con el modelo de Jean Piaget. Finalmente, se analizan tres tópicos - la sexualidad, la angustia y las "pruebas de transindividualidad" - como índices de resolución psicosocial de la problemática psíquica intra-individual.

Palabras clave: subjetividad individual, psicogénesis, sexualidad, angustia, pruebas de transindividualidad.
Abstract: In this paper the concept of individual subjectivity in the theory of the individuation of Gilbert Simondon is analyzed from a triple horizon. On the one hand, the main features of biological individuality are reconstructed and the degree difference between the vital and the psychic is introduced. On the other hand, that difference is explained in terms of a reconfiguration of the affective and cognitive regime, establishing the problematic and self-problematic nature of the individual, and analyzing a series of psychogenetic elements relating the simondonian theory with the model of Jean Piaget. Finally, three topics — sexuality, anxiety and "transindividuality proofs" - are analyzed as elements of psychosocial resolution of the intraindividual problems.

Keywords: individual subjectivity, psychogenesis, sexuality, anxiety, transindividuality proofs.

1 Este artículo de reflexión es producto de investigaciones doctorales y posdoctorales financiadas por el Consejo Nacional de Investigaciones Científicas y Técnicas (CONICET, Argentina). Una versión preliminar de este trabajo se encuentra plasmada en un parágrafo de la tesis de Doctorado (defendida en 2017), y la actual presentación retoma, refina y sistematiza dichos contenidos.

2 Doctor en Filosofía por la Universidad de Buenos Aires. Jefe de Trabajos Prácticos en las asignaturas Ética y Problemas Especiales de Ética del Departamento de Filosofía (Facultad de Filosofía y Letras, Universidad de Buenos Aires, Argentina). Becario postdoctoral del Consejo Nacional de Investigaciones Científicas y Técnicas (CONICET, Argentina) e investigador con sede en el Centro de Historia Intelectual de la Universidad Nacional de Quilmes. Correo electrónico: jmheredia@filo.uba.ar; https://orcid. org/0000-0002-4363-9811 


\section{Introducción}

En un importante estudio sobre la filosofía de Gilbert Simondon, Andrea Bardin (2015) ha llamado la atención sobre el carácter equívoco que el concepto de individuo asume en la obra del filósofo francés contrastando dos definiciones. La primera afirma, desde un horizonte epistemológico, que "no puede haber ciencia sino del individuo" (Simondon, 2005a, p. 553) 3 . La segunda, por el contrario, asume una serie de premisas metafísicas y concluye que — en el caso de los seres vivientes — "con todo rigor, no se puede hablar de individuo, sino de individuación” y completa afirmando que el "individuo no es un ser sino un acto, y el ser es individuo como agente de ese acto de individuación a través del cual se manifiesta y existe" (Simondon, 2015b, p. 236). Bardin (2015, pp. 4-5) concluye que esta aparente contradicción sería expresión de la crisis de la categoría de "identidad", y que se compatibiliza desde el momento en que se advierte que Simondon define al individuo como un complejo de estructura y operación, siendo la primera manifestación de lo individuado en el individuo y apuntando la segunda a tematizar el proceso activo (y transductivo) a través del cual se constituye y se transforma; fundiéndose este doble estatuto en la idea de individuo en tanto "sistema metaestable" —es decir, no idéntico a sí mismo-.

Esta reconstrucción está bien fundada, pero — a partir de ella y asumiendo otra perspectiva - se plantea el problema de cómo pensar al medio porque, según Simondon (2015b), el desfasamiento de la realidad preindividual hace aparecer no a un individuo aislado e independiente, sino a la "pareja individuo-medio" (pp. 415-416). El problema del estatuto del individuo, entonces, se desdobla pues no parece posible hipostasiar la pareja individuo-medio con la pareja estructura-operación. En efecto, mientras que la primera pareja traduciría la relación funcional esencial de un sistema abierto con su entorno, la segunda traduciría una dualidad inmanente al individuo viviente; dualidad que expresaría dos modos de relación posibles con el medio: un modo definido por estructuras y funciones individuadas y específicas que permitirían

\footnotetext{
3 Traducción propia, al igual que las citas de Sur la Psychologie (2015a).
} 
el mantenimiento de procesos homeostáticos y autorreguladores mediante la actividad moduladora, otro modo definido por una operación de transducción mediante la cual el individuo singular - en tanto "teatro y agente de una relación" (Simondon, 2015b, p. 61) - resuelve una incompatibilidad derivada del hecho de que la pareja que forma con el medio se ha problematizado, demandando nuevas estructuras y funciones ${ }^{4}$. De modo tal que el problema del individuo se desdobla en dos series, por un lado, la pareja individuo-medio (modelo de la individualidad biológica, que se expresa en la resolución de problemáticas prácticas y en el mantenimiento de un equilibrio metaestable que "es condición de vida") y, por el otro, el estatuto del individuo en tanto portador de una problemática inmanente (esto es, su carácter auto-problemático, el hecho de que comporta una relación consigo mismo).

En La individuación a la luz de las nociones de forma e información, la intención de Simondon en relación al individuo viviente es doble. Quiere resituar al individuo en el ser, mostrando que no se trata de una realidad aislada, independiente e idéntica a sí misma, sino que el individuo es relativo. Y lo es en dos sentidos: por un lado, depende de un medio asociado que le es esencialmente complementario y forma parte de un sistema de individuación que explica su génesis y su devenir. Pero, por otro lado, Simondon subraya que, si bien el individuo es una realidad doblemente relativa, no por ello pierde consistencia, ni se disuelve en un ser indiferenciado o en un devenir vertiginoso que lo vuelve insignificante. El punto de partida que asume Simondon (2015b) para pensar la consistencia de la individualidad animal es la unidad psicosomática tal como la tematiza Kurt Goldstein, irreductible al bisustancialismo cartesiano o bergsoniano: "es lo psicosomático el modelo de lo viviente; lo psíquico y lo somático son solo casos límites, nunca ofrecidos en estado puro" (p. 343).

Para Simondon, la individualidad viviente tiene un carácter problemático, una causalidad circular, una realidad relacional tanto en los animales como en los seres humanos; no hay una diferencia de naturaleza entre ambos que

4 Este desdoblamiento se confirma en la crítica que Simondon formula a Kurt Lewin, según la cual en éste, "la pareja generadora de disparidad es la relación individuo-mundo, no una dualidad de la que el individuo sería inicialmente portador" (Simondon, 2015b, p. 264). 
permita distinguir una esencia humana y fundar una antropología, sino que se plantea una diferencia de grado derivada de la frecuencia con la que se manifiestan en cada uno las problemáticas psíquicas. Mientras que en los animales éstas son raras y excepcionales (siendo recurrentes, por el contrario, las problemáticas vitales que se plantean en el sistema individuo-medio y frente a las cuales se poseen esquemas operatorios específicos), en los seres humanos las problemáticas psíquicas son mucho más asiduas y se expresan en una densificación, una ralentización y una radicalización de la relación del individuo consigo mismo (cf. Simondon, 2015b, p. 201). Es decir, la individualidad psicosomática tiende a manifestar no sólo un carácter problemático, sino también auto-problemático.

A efectos de contribuir a la elucidación del concepto de subjetividad individual en Simondon, en lo sucesivo, abordaremos tres cuestiones. En primer lugar, analizaremos algunos elementos que hacen a la consistencia de la individualidad vital, tematizando los rasgos del individuo biológico en términos funcionales y en correlación con su medio asociado. En segundo lugar, analizaremos el pasaje a la "vía transitoria" psíquica y destacaremos la redefinición del rol de la afectividad para pensar el carácter auto-problemático del individuo. Por último, y teniendo como índice la centralidad de las dinámicas afectivo-emotivas en el seno de la individualidad psicosomática, reflexionaremos sobre los tres caminos que Simondon plantea para pensar y trascender el carácter auto-problemático del individuo en dirección al descubrimiento y la constitución de una realidad transindividual (dimensión psicosocial dentro de la cual se resuelve y estabiliza el conflicto del individuo consigo mismo, realizándose como personalidad humana, y como expresión de grupos de interioridad, a través de individuaciones colectivas) ${ }^{5}$.

5 En este trabajo nos centraremos en la tematización de la individualidad psicosomática y sus presupuestos biológico-etológicos, psicológicos y metafísicos, poniendo relativamente entre paréntesis la realidad psicosocial y transindividual con la cual se encuentra íntimamente asociada. 


\section{La individualidad viviente}

Desde un punto de vista estrictamente funcional e independientemente de toda génesis, Simondon (2015b) identifica un primer centro de la individualidad viviente en el régimen de información con el cual se asocia al medio. En este sentido, conforme una teoría de raíz fisiológico-cibernética, el individuo animal aparece como un proceso continuo de integración - sensación, percepción, memoria- - y un proceso discontinuo de diferenciación — acciónenlazados, condensados y condicionados por una instancia intermedia, por un "centro de información", "donde el individuo almacena la información pasada y mediante el cual comanda, supervisa, inhibe o facilita (...) el pasaje de una información centrípeta a una reacción centrífuga. Lo que define la individualidad es la existencia de ese centro a través del cual el ser se gobierna y modula el medio" (pp. 238-239) ${ }^{6}$. Dicho centro es la "zona autónoma” del individuo, pero esta autonomía no debe ser confundida con una suerte de independencia. Simondon niega explícitamente que la separación anatómica pueda ser un criterio válido para pensar la individualidad; de hecho, el individuo viviente es a la vez dependiente y autónomo. Es dependiente porque está esencialmente asociado a un medio y se encuentra en permanente interacción con otros individuos que lo determinan parcialmente, es autónomo porque puede "funcionar según un proceso de resonancia interna que puede ser inhibidor respecto de los mensajes recibidos” y porque, si bien está en interacción con otros individuos, "la zona de conservación y de recurrencia de la información está limitada a los individuos; cualquiera sea la intensidad de la acción recíproca, cada individuo reacciona a su manera" (Simondon, 2015b, p. 243).

De modo que, desde el punto de vista funcional, la individualidad del individuo viviente anida en el régimen de información, es "la recurrencia de la información centrípeta y luego centrífuga la que marca los límites de la individualidad" (Simondon, 2015b, p. 240). Y la velocidad con la cual se opera la causalidad circular, es decir, la velocidad en la transmisión y propagación de las señales de información centrípetas — suministradas por los sentidos- y

6 Cursivas nuestras. 
las señales de información centrífugas — productoras de reacciones, posturas, gestos, actos-, permiten distinguir distintos grados de individualidad. Así, por ejemplo, mientras que en los mamíferos la velocidad de propagación de las señales de información a través del influjo nervioso "es en general de varios metros por segundo", en las colonias de metazoarios la conducción de las señales de información se efectúa por vía química y es cien veces más lenta, fenómeno que expresa la existencia en los primeros de un régimen de información fuertemente centralizado y, con él, una mayor consistencia individual (cf. Simondon, 2015b, pp. 238-243). Esta diferenciación entre distintos regímenes de información comprometería no solo a los vivientes sino también a las máquinas cibernéticas, pues desde un punto de vista puramente funcional, el modo a través del cual éstas procesan las señales de información y reajustan su comportamiento en función del medio resultaría análogo y sería pasible del mismo análisis. No obstante, a diferencia de la cibernética de Wiener, para Simondon (2007) esta analogía no es sostenible:

Lo viviente transforma la información en formas, el a posteriori en a priori; pero este a priori está siempre orientado hacia la recepción de la información a interpretar. La máquina, por el contrario, fue construida según un cierto número de esquemas y funciona de manera determinada (p. 154) ${ }^{7}$.

La existencia de un centro de información, que en los animales superiores y en los mamíferos se manifiesta plenamente en un sistema nervioso fuertemente centralizado, se va a vincular con un segundo centro de la individualidad que Simondon asociará fundamentalmente a la afectividad. En efecto, las tres funciones fisiológicas que la cibernética generalizará para pensar el comportamiento de distintas entidades comunicativas — esto es, las funciones receptoras, centrales y efectoras - (cf. Wiener, 1960, p. 85), serán plenamente asumidas por el filósofo francés dando lugar a la idea según la cual "existiría una profunda trialidad” en el ser viviente (cf. Simondon, 2015b, p. 196).

7 En este punto, es posible advertir que la posición simondoniana respecto del individuo viviente se diferencia de la de J. von Uexküll, encaminándose hacia una temporalización de la instancia trascendental - es decir, de las formas a priori de percepción, de la subjetividad de especie, de los esquemas operatorios instintivos, etc.- que, a través de una radicalización de la causalidad circular, reivindicará las relaciones diferenciales por sobre las tendencias específicas. 
Ahora bien, la diferencia que pondrá aquí Simondon (2015b) para conceptualizar el comportamiento de los animales, será vincular la instancia intermedia entre la percepción y la acción —que, desde un punto de vista fisiológico, refiere al sistema nervioso central — a la función afectiva; existiría en el viviente, entonces, "una estructura triádica de funciones perceptivas, activas y afectivas" (p. 202). La afectividad cumple un rol regulador y, en tanto sede de la resonancia interna del individuo viviente, "realiza la integración de las [dos funciones] precedentes, al mismo tiempo que su diferenciación mediante la actividad de recurrencia causal” (p. 196). De modo que nos encontramos con tres funciones: una función perceptiva que reside en los órganos sensoriales específicos y que, asociada a la memoria, realiza un proceso continuo; una función activa que remite a los órganos efectores y que se efectúa de modo discontinuo; una función afectiva que, en tanto transductor interno privilegiado, opera la regulación entre la percepción integradora y la acción diferenciadora, entre lo uno y lo múltiple, entre lo homogéneo y lo heterogéneo; cualificando, condensando y disponiendo estas dos funciones en el tiempo — conforme una causalidad circular- y orientando al ser viviente en relación consigo mismo. Esta comunicación entre dos funciones diferentes sería posible porque la afectividad es polarizada y polarizante, siendo relacional por esencia.

De este modo, según Simondon (2015b), la afectividad es sede de la resonancia interna y de la consistencia del individuo viviente, el devenir afectivo proporciona "cualidades reguladoras que sirven a la relación entre la integración [perceptiva, memorativa, cognitiva] y la diferenciación [activa]”, y estas cualidades emergen de la "reactividad a través de la cual lo viviente aprecia su propia acción” (p. 195). Así,

[...] es gracias a esta orientación del ser en relación consigo mismo, a esta polarización afectiva de todo contenido y de todo constituyente psíquico, que el ser conserva su identidad. La identidad parece fundada sobre la permanencia de esta orientación en el curso de la existencia, orientación que se despliega gracias a la cualificación de la acción y del conocimiento (p. 198).

En este sentido, el funcionamiento de la afectividad en el devenir vital revela que ésta es sede de procesos de individuación internos —o individuali- 
zaciones - que, conforme la asunción de nuevas cualidades e informaciones, singularizan y modifican constructivamente las pautas de comportamiento del individuo, convirtiendo lo a posteriori en a priori. Esto último se comprende desde el momento en que se advierte que, para Simondon (2015b), la afectividad —y los procesos de causalidad circular que ella cualifica y condensason índice de la temporalidad: "la identidad del ser viviente está hecha de su temporalidad" (p. 199), "la afectividad es integración autoconstitutiva a estructuras temporales” (p. 329) y, así como la sensación indica la inserción del individuo en el medio, la afectividad indica su inserción en el devenir (p. 328).

Ahora bien, en esta representación del individuo biológico predominan, y son más frecuentes, las problemáticas somáticas que emergen en la relación individuo-medio y no las situaciones psíquicas. Es decir, prevalece una concepción funcional en la consideración del comportamiento y, si bien se tematiza el rol de la afectividad y la temporalidad como elementos de la problemática interna del animal, éstos asumen un rol regulador y permiten - junto con el "centro de información" - la coordinación de las funciones perceptivas y activas, y con ellas, la modulación del medio. En este sentido, "la finalidad biológica es homeostática y apunta a obtener una satisfacción del ser en un mayor estado de equilibrio" (Simondon, 2015b, p. 360). Ello no implica, sin embargo, que el sentido del comportamiento animal sea definido en términos de adaptación. Simondon retoma aquí, casi íntegramente, la conceptualización de Kurt Goldstein: en tanto unidad psicosomática dinámica y activa, el organismo no se adapta, sino que se auto-realiza componiéndose con el medio ambiente, conquistando en él y con él desempeños adecuados que le permiten mantener sus tensiones — su equilibrio metaestable — dentro de un rango medio - "constantes del organismo"- ${ }^{8}$.

8 Como se desprende de su tesis doctoral principal (2015b), así como de sus estudios sobre psicología (2015a), Simondon retoma varios elementos del esquema de Kurt Goldstein. Ejemplo de ello son la analogía que presenta la pareja individuo-medio simondoniana y el par organismo-medio ambiente goldsteiniano, la similar crítica de ambos al concepto de adaptación en biología y en psicología, y la común reivindicación — contra Lewin — de las ideas de homeostasis y de equilibrio metaestable. Para un análisis más detallado de la relación Simondon-Goldstein, véase Heredia, 2018, pp. 388-396. 


\section{Elementos de psicogénesis}

¿Cómo surge la dimensión psíquica y qué relación guarda con lo somático en el ser viviente individuado? Simondon niega que exista algo así como una "individuación psíquica” que daría lugar a un ser post-biológico y puramente espiritual, como plantean en general las teorías bisustancialistas y, en particular, Max Scheler a fines de la década del veinte. Afirma, por el contrario, que la aparición de lo psíquico es producto de "una individualización de lo viviente" que desdobla lo somático y lo psíquico como dos funciones diferentes, aunque complementarias: "El ser individuado no posee en el comienzo un alma y un cuerpo; se construye como tal al individualizarse, desdoblándose etapa por etapa" (Simondon, 2015b, p. 339). En efecto, según Simondon, producto de la cada vez mayor frecuencia de problemáticas irresolubles en términos puramente vitales, se franqueará un umbral y se producirá un desdoblamiento psíquico de lo vital, deviniendo el individuo psicosomático sede de una dualidad entre las problemáticas perceptivo-activas y las afectivo-emotivas. En este punto, se plantea una distinción entre los conceptos de individuación e individualización: mientras que el primer proceso tematiza la emergencia de los seres vivientes individuados y su devenir relativo a un medio, el segundo tematiza procesos de individuación inmanentes al individuo biológico individuado y encuentra su región problemática en la relación del ser consigo mismo; Simondon (2015b) clarifica este punto señalando que "La individualización es tanto más acentuada cuanto a más situaciones críticas, de las que llega a salir airoso al desdoblarse en el interior de sí mismo, se encuentra sometido el viviente. La individualización del viviente es su historicidad real" (p. 339). ${ }^{9}$ En este sentido, si bien los animales no estarían desprovistos de psiquismo, la emergencia de éste en situaciones críticas muy puntuales en el curso de una vida no alcanzaría a desdoblar la unidad psicosomática de modo duradero, sino que dicha unidad seguiría existiendo en el ser individuado bajo la forma de "pares somatopsíquicos sucesivos, parcialmente coordinados entre sî" (Simondon, 2015b, p. 339).

9 Para un análisis de los conceptos simondonianos de individuación e individualización, véase Gil, 2016, pp. 52-77. 
La vida aparece, así, desde el punto de vista del individuo biológico, como un proceso que - en el marco de la relación con el medio- desdobla y enlaza esquemas psíquicos y especializaciones somáticas. En tanto el viviente sea capaz, por un lado, de asimilar las señales de información y acomodarlas a los esquemas de percepción-acción instintivos y, por otro lado, de variar parcialmente dichas formas e individualizar en sí los esquemas psíquicos suplementarios que necesita para poder sortear situaciones críticas, el umbral no se franquea (cf. Simondon, 2015b, pp. 338-339). Para explicar esta idea según la cual "toda individualización supone una individuación, pero añade algo a ella”, Simondon (2015b) plantea — para el caso del ser viviente en general-que

la conducta instintiva es aquella en la cual los elementos de la solución están contenidos en la estructura del conjunto constituido por el medio y el individuo; por el contrario, una conducta de reacción organizada es aquella que implica de parte del ser viviente la invención de una estructura (p. 345).

No obstante, cuando el recurso al psiquismo se vuelve frecuente, cuando las señales de información que emanan del medio no son fácilmente integrables y/o presentan problemas vitales que obligan a una recurrente refundición de las formas perceptivo-activas, los esquemas psíquicos se multiplican, se imbrican unos en otros, entran en un estado de resonancia interna y una suerte de vacilación fundamental puebla al viviente, que se ve invadido por una afectividad sin referencia y por una incompatibilidad de esquemas que lo ponen como problema para sí mismo.

Si en el plano del comportamiento animal la referencia implícita es Kurt Goldstein y la unidad de análisis privilegiada la "composición entre el organismo y el medio ambiente" (Simondon, 2015a, p. 116), en lo relativo a la psicogénesis Simondon replicará las tesis de Jean Piaget y, con ellas, prolongará el doble aspecto que hemos visto a propósito del centro de la individualidad vital —esto es, el régimen de información y la afectividad—. En efecto, para Piaget, la génesis y el desarrollo psíquico ha de ser pensado siempre conforme dos aspectos complementarios, uno estructural y otro energético, que expresan el carácter unitario del comportamiento. En este sentido, en un libro en el 
cual recapitula junto a Inhelder el conjunto de su teoría psicogenética, Piaget (1984) plantea:

\begin{abstract}
El aspecto cognoscitivo de las conductas consiste en su estructuración, y el aspecto afectivo, en su energética (...). Esos dos aspectos son, a la vez, irreductibles y complementarios: no hay que extrañarse, pues, de hallar un paralelismo notable entre sus respectivas evoluciones. De un modo general, en efecto, mientras el esquematismo cognoscitivo pasa de un estado inicial centrado sobre la acción propia a la construcción de un universo objetivo y descentrando, la afectividad de los mismos niveles sensorio-motores procede de un estado de indiferenciación entre el yo y el "entorno" físico y humano para construir a continuación un conjunto de cambios entre el yo diferenciado y las personas (sentimientos interindividuales) o las cosas (intereses variados, según los niveles) (p. 31).
\end{abstract}

Si tomamos como hilo conductor estas "correlaciones cognoscitivo-afectivas” y sus distintos estadios y períodos, podremos ver el modo a través del cual Simondon tematiza esta individualización psíquica de lo viviente y su diferencia de grado con el ser biológicamente individuado. Este último, como vimos, está dominado por las problemáticas somáticas que emergen de su relación con el medio ambiente, es decir, su actividad está volcada casi íntegramente a la acción, dominan en él esquemas sensorio-motores y carece de una comprensión cabal de la diferencia entre su ser y su mundo — esto último, precisamente, es lo que hace posible que la afectividad juegue un rol regulador-. Desde este horizonte, el animal adulto es como un niño de pocos años, un niño que no se ha elevado aún más allá de su realidad espaciotemporal inmediata, que no puede entrar en relación con un objeto en cuanto tal, cuya función simbólica no se ha diferenciado lo suficiente, que es incapaz de pensamiento formal, etc. Y es precisamente esta analogía la que refuerza la recurrente apelación simondoniana a la idea de neotenia para explicar la psicogénesis: "lo psíquico interviene como una ralentización de la individuación de lo viviente, una amplificación neoténica del estado primero de esa génesis; hay psiquismo cuando lo viviente no se concretiza completamente y conserva una dualidad interna" (Simondon, 2015b, p. 200). En este sentido, por ejemplo, mientras que un león tarda un año en poder valerse por sus propios medios, siendo desde entonces autónomo en lo que hace a las actividades de ataque, defensa, alimentación, reproducción, etc., en lo seres humanos el desarrollo de las estructuras cognitivo-afectivas 
básicas demanda más de una década. Y es esta ralentización potencializadora la que explicaría su capacidad para construir estructuras psíquicas cada vez más complejas, integrando cada vez más esquemas e informaciones y re-estructurando periódicamente la economía que los organiza conforme un "equilibramiento por autorregulación” (cf. Piaget e Inhelder, 1984, p. 158).

Cabe reponer, entonces, el ingreso de lo viviente en esta "vía transitoria" psíquica en función de los dos aspectos evocados. Respecto de la génesis de las estructuras cognitivas, Piaget e Inhelder (1984) subrayan que éstas encuentran su origen en un progresivo proceso de interiorización de esquemas de acción: "la inteligencia procede de la acción en su conjunto, porque transforma los objetos y lo real, y el conocimiento, cuya formación puede seguirse en el niño, es esencialmente asimilación activa y operatoria" (p. 38). Por "asimilación" hay que entender no una recepción pasiva de señales de información, sino una integración activa de éstas en marcos previos —esquemas de origen hereditario y/o producto de la interacción sensoriomotora con el medio-, integración que va afinando y enriqueciendo los esquemas con cada nueva experiencia. Este proceso se completa con el concepto piagetiano de "acomodación", que expresa la modificación relativa de los esquemas mentales conforme la variabilidad que presentan señales de información no asimilables sin dificultad a los esquemas previos. Al respecto, Piaget indica:

No puede dudarse que la vida mental es también acomodación al medio. La asimilación nunca puede ser pura, porque al incorporar nuevos elementos a sus esquemas anteriores, la inteligencia modifica constantemente dichos esquemas para ajustarlos a los nuevos elementos (citado en Richmond, 1972, p. 101).

Todo lo cual da lugar una representación en la cual la interacción de procesos de asimilación y de acomodación establece constructivamente - por autorregulación - sucesivas etapas de equilibrio y estabilidad, en un desarrollo cognitivo que en el niño va desde los esquemas sensoriomotores primarios hasta el pensamiento formal y lógico-matemático.

Desde este horizonte, entonces, la psicogénesis depende esencialmente de la relación entre el individuo y el medio, "la inteligencia es un caso particular de adaptación biológica", "es una organización” y "su función es estructurar el 
universo del mismo modo que el organismo estructura su medio inmediato" (Piaget, 1936, citado por Richmond, 1972, p. 97). Piaget se opone tanto al innatismo como al empirismo para explicar este proceso, subrayando la interdependencia entre el organismo y el medio en el devenir de la "viventia" (cf. Richmond, 1972, pp. 96 y ss). Simondon replica este modelo genético y, como hemos visto recientemente, una de las formas que emplea para pensar la amplificación de lo psíquico en lo viviente es la postulación de un momento en el cual las problemáticas prácticas que plantea el medio ya no son resolubles y se interioriza la dificultad. En este sentido, afirma que "el verdadero psiquismo aparece cuando las funciones vitales ya no pueden resolver los problemas planteados a lo viviente, cuando esta estructura triádica de las funciones perceptivas, activas y afectivas ya no es utilizable", y agrega que esta situación revela que "el ser viviente ya no posee en sí mismo el suficiente ser como para resolver los problemas que le son planteados" (Simondon, 2015b, p. 202). De modo que, según esta representación, cabe pensar el origen de la inteligencia a partir de la interiorización de esquemas de acción y su desarrollo en función del devenir de la pareja individuo-medio.

La interpretación del pasaje desde lo vital a lo psíquico en términos del desarrollo de la estructura cognitivo-activa, se complementa en Simondon con una transmutación del rol de la afectividad, que deja de ser un elemento regulador para devenir fuente de problemática psíquica —es decir, resonancia interna del ser consigo mismo-.

La diferencia esencial entre la simple vida y el psiquismo consiste en que la afectividad no juega el mismo papel en esos dos modos de existencia; en la vida, la afectividad posee un valor regulador; se eleva sobre las otras funciones y asegura esa permanente individuación que es la vida misma; en el psiquismo, la afectividad es desbordada; plantea problemas en lugar de resolverlos, y deja no resueltos los problemas de las funciones perceptivo-activas. El ingreso a la existencia psíquica se manifiesta esencialmente como la aparición de una problemática nueva, más alta, más difícil, que no puede recibir ninguna auténtica solución en el interior del ser viviente propiamente dicho, concebido en el interior de sus límites como ser individuado; la vida psíquica no es por tanto ni una solicitación ni una reorganización superior de las funciones vitales, que continúan existiendo bajo ella y con ella, sino una nueva inmersión en la realidad preindividual, seguida de una individuación más primitiva. (Simondon, 2015b, p. 201). 
Si retomamos los términos de Piaget, esta "inmersión en la realidad preindividual” expresa una suerte de reverberación energética en el seno del sujeto, sobretensión afectiva que resulta correlativa a la incompatibilidad e incoordinación de los esquemas cognitivo-activos frente a la situación crítica. Esta última corta la continuidad entre el sujeto y el mundo, neutraliza la función reguladora de la afectividad y pone al individuo como problema para sí mismo. Esta situación de crisis y desadaptación, sin embargo, es también una situación de potencialización (cf. Simondon, 2015b, p. 504) y obliga al ser a sobrepasarse inventando nuevas estructuras y funciones - que, englobando la dificultad superada, re-estructuran las correlaciones cognitivo-afectivas y conquistan un nuevo equilibrio metaestable $-{ }^{10}$. Y es precisamente en este punto que aparece un tercer nivel en la representación del devenir del sujeto psicosomático: "la individuación solo tiene lugar una vez; la individualización es tan permanente como la percepción y las conductas corrientes; la personalidad, en cambio, es del dominio de lo cuántico, de lo crítico" (Simondon, 2015b, p. 340).

Siguiendo el hilo de la problemática afectivo-emotiva, la constitución de la personalidad depende según Simondon de una serie de participaciones psicosociales e individuaciones colectivas pero, desde el punto de vista del sujeto psicosomático, se revela en el "dominio de lo cuántico, de lo crítico" y es con su discontinuidad que se re-estructura la relación hasta entonces dominante entre la individuación y la individualización, es decir, el conjunto de estructuras y funciones que organizan el comportamiento del individuo: "se edifican estructuras de personalidad que duran un cierto tiempo, resisten a las dificultades que deben asumir y luego, cuando ya no pueden mantener individuación e individualización, se rompen y son reemplazadas por otras" (Simondon, 2015b, p. 340). El proceso de "personalización", entonces, estructura y re-estructura a través de saltos discontinuos la relación entre la historicidad radical, contingente y empírica de la individualización y el proceso único de individua-

10 En el curso Imaginación e invención (1965-1966), donde la sombra de Piaget es inocultable, Simondon repensará su psicogénesis y el devenir de la pareja individuo-medio a partir del concepto de imagen mental. En este sentido, postulará un ciclo de la imaginación y derivará de allí las condiciones de posibilidad para una invención psíquica, es decir, para una reestructuración del sistema de imágenes mentales a través del cual el sujeto se articula con el mundo (cf. Simondon, 2013). 
ción que define al individuo biológicamente individuado ${ }^{11}$. La personalidad es un mixto, reúne las funciones perceptivo-activas y cognitivo-activas con las problemáticas afectivo-emotivas, y en tanto tal constituye lo que Simondon (2015b) llama "lo concreto humano" (p. 335). Aquí, nuevamente, no estamos lejos de Piaget, para quien "toda la formación de la personalidad está dominada por la búsqueda de una coherencia y de una organización de los valores que excluyan las fisuras interiores" y supone "conflictos o crisis y re-equilibraciones" (Piaget e Inhelder, 1984, p. 157). Y, para Simondon (2015b), la personalidad "se construye por crisis sucesivas", "se construye por estructuraciones sucesivas que se reemplazan, "integrando las nuevas [estructuraciones] subconjuntos de las más antiguas, y dejando también de lado un cierto número de estas como restos inutilizables" (p. 340). Y agrega que es precisamente en "la relación sucesiva de estas fases de personalidad [que] yace el fundamento del problema de la trascendencia" (p. 340). Hay, como diría Piaget (1984), no un "plan preestablecido, sino una construcción progresiva tal que cada innovación sólo se hace posible en función de la precedente" (p. 155).

\section{De lo psicosomático a lo transindividual}

Cabe subrayar que para Simondon (2015b) el ingreso en la realidad psíquica es "una vía transitoria" y que el psiquismo aparece como "lo transindividual naciente" (p. 203) ${ }^{12}$. En efecto, la "nueva inmersión en la realidad prein-

11 Simondon vincula este "proceso único de individuación” con lo trascendental kantiano, luego lo relativiza al modo existencialista — en el sentido de que la existencia precede y constituye a la esencia- y concluye proponiendo pensar lo trascendental como campo de lo problemático — esto es, como una realidad preindividual de carácter energético y afectivo que anida en el sujeto y que, movilizando en él un conjunto de "fuerzas organizables", opera como condición de las sucesivas re-estructuraciones de la personalidad- (cf. Simondon, 2015b, pp. 334-335). En este sentido, como veremos, pone como ejemplo privilegiado de "relación al nivel de la individuación" a la sexualidad, ésta aparece como un mixto de ilimitado y limitado, de naturaleza preindividual y de individualidad, incitando a lo colectivo y a lo espiritual (cf. 2015b, pp. 391-392).

12 En este punto, Simondon sigue una tendencia de la época muy clara, relativa a pensar la articulación entre lo psíquico y lo social escapando a las antinomias entre la psicología y la sociología. Aquí, nuevamente, Piaget (1986) destaca como referencia epistemológica: "no existe una serie de tres términos sucesivos: biología $\bigotimes$ psicología $\bigotimes$ sociología, sino más bien un paso simultáneo de la biología a la psicología y a la sociología unidas, ya que estas dos últimas disciplinas tratan el mismo objeto sólo que desde dos puntos de vista distintos y complementarios" (p. 21). 
dividual" que plantea la problemática psíquica en tanto incompatibilidad y tensión del ser consigo mismo, es irresoluble en términos intra-individuales y conduce a individuarse en lo colectivo, es decir, a trascender la individualidad psicosomática y constituirse una personalidad de grupo, participando en grupos de interioridad (cf. 2015b, pp. 377 y ss., 387 y ss.). Hay, entonces, una individuación psíquico-colectiva que, si bien no rompe con la individuación vital, inaugura un dominio psicosocial perdurable que es irreductible a la relación funcional con el medio asociado. Encontramos aquí a la realidad transindividual, tercera fase del ser, tercera dimensión que tensiona el devenir de la subjetividad — siendo segunda la pareja individuo-medio y primera lo preindividual vivido como inquietud afectivo-energética-. Ahora bien, es posible divisar - a propósito del desdoblamiento psíquico de lo viviente y el ingreso en la fase transindividual del ser- tres elementos que asumen un carácter tanto psicosomático como metafísico, y que indican el carácter esencialmente psicosocial del psiquismo individual. Estos elementos son la sexualidad, la angustia y las pruebas de transindividualidad.

En primer lugar, la sexualidad revela en los seres humanos la relatividad de la individualidad, el hecho de que el ser individual no posee en sí mismo su principio de existencia ni existe por sí. La sexualidad aparece entonces "como una inmanencia psicosomática de la naturaleza preindividual al ser individuado" (Simondon, 2015b, p. 392), indica una incompletitud y/o una sobre-individualidad esencial e innata, manifestándose como un sentimiento que hace brotar — desde el seno mismo del ser psicofísico— un deseo de amplificación y emparejamiento. De este modo, según Simondon, su sentido principal no es biológico ni meramente psicológico, no es primariamente ni imperativo específico de reproducción, ni pulsión orgánica individual, su significación eminente es metafísica: realiza la inherencia de lo ilimitado en lo limitado, "hace comunicar individualidad y naturaleza" y "esta traducción de lo ilimitado en lo limitado preserva al ser de la aseidad y lo priva correlativamente de una individuación completa" (Simondon, 2015b, 391). En este marco, asimismo, la sexualidad no es ni puramente preindividual ni puramente individual, está a mitad de camino entre el ápeiron y el individuo; es "un mixto de naturaleza y de individuación; es una individuación en suspenso, suspendida en la 
determinación asimétrica de lo colectivo elemental, de la dualidad unificada de la pareja" (p. 392). Ella no es lo colectivo ni la espiritualidad, pero es ya "incitación a lo colectivo" e "incitación a la espiritualidad; poniendo el ser en movimiento, permite al sujeto comprender que no es individuo cerrado, que no posee aseidad" (p. 392). La sexualidad polariza al ser y lo saca de sí mismo. Esta caracterización metafísica le permite a Simondon ver en la sexualidad un principio de auto-trascendencia hacia lo "colectivo elemental", deviniendo por ello modelo de "la relación al nivel de la individuación” y cemento primero de la individuación colectiva en la constitución de la personalidad (cf. 2015b, p. 335). Es decir, mientras que la individualización indica la divergencia, la diferenciación y la singularización empírica del ser individual, la proto-individuación psíquico-colectiva que moviliza la sexualidad representa el movimiento inverso, siendo elemento de integración, de compatibilización, de articulación y de descubrimiento de significaciones relacionales. La configuración de ambas tendencias - y sus sucesivas re-configuraciones — indican el proceso de personalización —que, por otra parte, no encuentra sólo en la sexualidad el elemento individuante-.

En segundo lugar, Simondon no innova para nada en la recuperación del concepto de angustia, semánticamente ya recubierto por un denso conjunto de lecturas que le son plenamente contemporáneas y que encuentran en Heidegger, Goldstein y Sartre tres referencias ineludibles: el primero - recuperando los desarrollos de Kierkegaard - la eleva al rango de concepto metafísico, haciendo de ella el temple de ánimo en el cual se revela la nada como sumersión de todas las cosas en la indeterminabilidad (cf. Heidegger, 2009, pp. 26 y ss.); el segundo la interpreta en términos psicológicos como "reacción catastrófica" que paraliza al sujeto e inhibe su movimiento de auto-realización a través de desempeños ordenados (cf. Goldstein, 1995, pp. 48 y ss.); el tercero la aborda en clave ético-política y, vinculándola con la responsabilidad y con aquello que demanda decisión y elección, hace de ella "conciencia de la libertad" y "obligación perpetuamente renovada de rehacer el Yo" (cf. Sartre, 1997, pp. 69-70; 1999, pp. 15 y ss.). Simondon va a retomar parcialmente todos estos elementos y, fundiéndolos, forjará su propia noción de angustia. Con Heidegger, conviene en asignar a la angustia el carácter de índice meta- 
físico, pero niega rotundamente que ésta pueda ser expresión de la "nada" y que la nada pueda fundamentar, a su vez, a la negatividad. Para Simondon, bergsonianamente, la nada y la negatividad sólo tienen una realidad de orden lógico y psicológico, no ontológico ni ontogenético (cf. 2015b, pp. 198 y ss). En este punto, Simondon está mucho más cerca del monismo de Goldstein que de Heidegger, Merleau-Ponty y Sartre. En contraposición a estos últimos, Simondon plantea que para Goldstein "la estructuración es siempre estructuración en función de lo que es, no en función de lo que no es, lo que conduce a una crítica de Scheler y de las doctrinas fenomenológicas que hacen un lugar a la idea de nada" (2015a, p. 115). No es la nada lo que explica la posibilidad y la necesidad subjetiva de trascenderse y trascender lo dado, sino la sobrecarga de realidad preindividual, la reverberación energética de lo ilimitado en la finitud del individuo limitado. Simondon sin dudas suscribe la máxima goldsteiniana según la cual "no hay nada 'negativo' en la naturaleza" (Goldstein, 1995, p. 146). En efecto, en la ontogénesis simondoniana la nada no cumple ningún rol y este es uno de los principales puntos que diferencian a su metafísica del existencialismo, del mismo modo que la recusación de la negatividad lo aleja del hegelianismo. No obstante, el carácter imperativo que asume en el sujeto psíquico la necesidad y/o el deseo de trascenderse, de superarse, de amplificarse, resulta similar y entrańa una normatividad análoga. Esta última es tanto psicológica y goldsteiniana — porque la angustia es una "reacción catastrófica” que hay que trascender con nuevos desempeńos activos-, como ético-política y sartreana — porque preanuncia la necesidad de individuarse en lo colectivo, participando y comprometiéndose en grupos de interioridad que son coextensivos a la personalidad del individuo- ${ }^{13}$.

Simondon (2015b) describe a la angustia como un verdadero callejón sin salida de la problemática afectivo-emotiva, "una emoción sin acción, un sentimiento sin percepción", "pura repercusión del ser en sí mismo" y agrega:

13 Esto último se muestra cabalmente en el concepto de elección. Así como Sartre (1999) apunta que todo acto individual compromete y presupone a toda la humanidad ("eligiéndome, elijo al hombre") (pp. 14-15), Simondon (2015b) plantea que la elección es una "actividad transindividual": "es descubrimiento de una relación de ser por la cual el sujeto se constituye en una unidad colectiva", "es descubrimiento e institución de lo colectivo", "es estructuración dentro del sujeto con otros sujetos; el sujeto es medio de elección al mismo tiempo que agente de dicha elección” (p. 394). 
Esta inmensa inflación del ser, esta dilatación sin límites que quita todo refugio y toda interioridad traduce la fusión, en el interior del ser, entre la carga de naturaleza asociada al ser individual y su individualidad; las estructuras y las funciones del ser individuado se mezclan unas con otras y se dilatan, ya que reciben de la carga de naturaleza ese poder de ser sin límites; lo individuado es invadido por lo preindividual; todas las estructuras son atacadas, las funciones animadas de una fuerza nueva que las vuelve incoherentes (p. 323).

Y si bien Simondon conjetura que quizás podría ser posible que, del seno de la angustia, nazca una suerte de individuación super-individual que permita al sujeto auto-trascenderse sin pasar por lo colectivo —adentrándose así en una "individuación desconocida”-, el sentido del concepto en la economía del discurso simondoniano apunta a mostrar el carácter indisociable de lo psíquico y lo colectivo, haciendo patente el hecho de que el sujeto psíquico es más que sí mismo y, en la medida en que no amplifique la carga de realidad preindividual que porta, se expone a la auto-aniquilación y a la locura.

En tercer lugar, Simondon presenta lo que denomina "prueba de transindividualidad", un mixto de soledad, aislamiento y experimentación que se expresa en experiencias excepcionales cargadas de afecto-emotividad y religiosidad, que revelan al ser individual la existencia de una realidad que lo sobrepasa, que en cierto sentido es independiente de él pero que, sin embargo, lo incluye:

El verdadero individuo es aquel que ha atravesado la soledad; lo que descubre más allá de la soledad es la presencia de una relación transindividual. El individuo encuentra la universalidad de la relación al término de la prueba que se ha impuesto, y que es una prueba de aislamiento (Simondon, 2015b, p. 356).

Estas "pruebas de la transindividualidad" implican una lógica de la afecto-emotividad radicalmente diversa a la angustia y alumbran, más allá de toda relación funcional y de todo vínculo inter-individual, el carácter sobre-inmanente y cuasi-trascendente que define la esencia afectivo-emotiva de lo transindividual — "base común de todas las fuerzas religiosas" y "fuente de todas las religiones", independientemente de sus contenidos y procesos de institucionalización (cf. 2015b, p. 356) —. En las pruebas de transindividualidad se revela no el conflicto entre lo preindividual y lo individuado, sino la sinergia 
entre la naturaleza y lo psicosocial en y a través de los individuos (cf. 2015b, p. 358). Ahí donde Heidegger encontraba, por detrás de la angustia, a la nada, Simondon encuentra, a través de las pruebas de la soledad, el aislamiento y la experimentación, a la intuición viva de la fase psicosocial del devenir del ser; realidad autoconstitutiva que se desprende de los individuos y que, en el mismo movimiento, los arraiga en grupos de interioridad. Y esta intuición serena de una trascendencia inmanente aporta una dimensión "de rebasamiento en relación al individuo" y le permite captar la realidad de una presencia psicosocial que le es anterior, interior y exterior (cf. Simondon 2015b, pp. 357-358). No obstante, a fin de cuentas, la conclusión ontogenética es la misma que con respecto a la sexualidad y la angustia porque el individuo no puede perdurar en un estado de aislamiento, soledad y experimentación, estas pruebas excepcionales están para ser atravesadas pero no para permanecer en ellas, son sólo puestas entre paréntesis, intuición invertida de una presencia psicosocial omnipresente y dinámica, dentro de la cual se sitúa y deviene el individuo humano.

\section{Conclusión}

El recorrido hecho nos permite subrayar una serie de aspectos de la teoría simondoniana de la subjetividad individual. En primer lugar, ya en su dimensión vital, hay un punto digno de atención y es la relación entre afectividad e información. La recepción de señales de información y el conjunto de actuaciones que éstas condicionan y propician, se encuentra atravesado globalmente por una dimensión afectiva. Para Simondon resulta de primera importancia comprender que el estado afectivo-emotivo del receptor condiciona de modo decisivo la eficacia de la señal incidente, dependiendo de ello que se produzca un proceso de individuación estructurante - in-formacióno un simple proceso de modulación que se vale de la señal para (re)ajustar un comportamiento ya estructurado ${ }^{14}$. Esta es una de las principales originalida-

14 Sobre esta cuestión, véase el importante artículo "La amplificación en los procesos de información" (1962) en Simondon, 2015c, pp. 137-162. 
des simondonianas con respecto a los modelos de la cibernética y la teoría de la información.

En segundo lugar, respecto de las dimensiones vitales y psíquicas de la individualidad, hemos mostrado, por un lado, que Simondon no sólo afirma la existencia de una diferencia de grado - y no de naturaleza - entre el ser humano y el animal, sino que también indica que dicha diferencia tiene lugar a partir de un cambio en el régimen afectivo-emotivo y en el cognitivo, proceso que intensifica la problemática del individuo consigo mismo y la superpone de modo duradero a la problemática vital de la relación funcional con el medio. Por otro lado, hemos llamado la atención respecto de la recuperación simondoniana de ciertos presupuestos retomados de la teoría de la unidad psicosomática de Kurt Goldstein, además de desplegar una serie de relaciones con el esquema de la psicogénesis de Jean Piaget. Esta última cuestión no ha sido objeto de análisis pormenorizados en los estudios sobre la filosofía de Simondon, privilegiándose en general la remisión a la ontogénesis de Arnold Gesell a la cual cita de modo explícito — adoptando la influencia piagetiana un carácter implícito pero, creemos, de gran importancia conceptual- . Todo ello nos ha permitido aportar elementos para elucidar la distinción simondoniana entre individuación, individualización y personalización, así como para pensar los momentos de continuidad y de discontinuidad en el despliegue de la subjetividad individual.

En tercer lugar, y siguiendo el hilo conductor de la redefinición del rol de la afectividad en el seno de la individualidad, hemos analizado tres elementos que asumen un carácter tanto psicosomático como metafísico y que indican la necesaria participación de la subjetividad individual en un orden de realidad psicosocial, apuntalando así la idea según la cual "el psiquismo lo psíquico es lo transindividual naciente” (Simondon, 2015b, p. 203). Recapitulando lo dicho al respecto, es posible advertir que la sexualidad representa una intensificación afectivo-emotiva sinérgica y propulsiva que conduce a la relación transindividual y dota al ser de un significado relacional, la angustia representa una alteración caótica e inflacionaria de la relación del ser consigo mismo, atrapando al ser individual en una espiral interior de disolución que lo paraliza, las pruebas de la soledad, el aislamiento y la experimentación representan 
el descubrimiento intuitivo de lo transindividual, la captación de su esencia espiritual y mística en tanto reunión de la naturaleza en grupos de interioridad. Los tres elementos son de carácter afectivo-emotivo e indican, desde el punto de vista de las experiencias psicosomáticas, distintos modos de acceso a la tercera fase del ser, fase resolutoria de la problemática intra-individual e integradora del individuo en un proceso de individuación más vasto. 


\section{ReferenCiAS}

Bardin, A. (2015). Epistemology and political philosophy in Gilbert Simondon. Dordrecht: Springer.

Gil, L.M. (2016). Psicología, trabajo e individuación. Bogotá: Editorial San Pablo.

Goldstein, K. (1995). The organism: a holistic approach to biology derived from pathological data in man. New York: Zone Books.

Heidegger, M. (2009). ¿Qué es metafísica?. Madrid: Alianza.

Heredia, J. M. (2018). Forma e individuación: Simondon y la Gestaltpsychologie. Eidos - Revista de Filosofía de la Universidad del Norte, 29, 366-399.

Piaget, J. (1986). Estudios sociológicos. Barcelona: Planeta DeAgostini.

Piaget, J. e Inhelder, B. (1984). Psicología del niño. Madrid: Morata.

Richmond, P. G. (1972). Introducción a Piaget. Madrid: Fundamentos.

Sartre, J. P. (1997). El ser y la nada. Barcelona: Altaya.

Sartre, J. P. (1999). El existencialismo es un humanismo. Buenos Aires: Losada.

Simondon, G. (2005). L'individuation à la lumière des notions de forme et d'information. (Traducción libre) Grenoble: Jérôme Millon.

Simondon, G. (2005a). "Analyse des critères de l'individualité". En L'individuation à la lumière des notions de forme et d’information. (553-558). Grenoble: Jérôme Millon.

Simondon, G. (2007). El modo de existencia de los objetos técnicos. Buenos Aires: Prometeo. 
Simondon, G. (2013). Imaginación e invención. Buenos Aires: Cactus.

Simondon, G. (2015a). Sur la psychologie. Paris: P.U.F.

Simondon, G. (2015b). La individuación a la luz de las nociones de forma e información (2a. ed.). Buenos Aires: Cactus.

Simondon, G. (2015c). Comunicación e información. Buenos Aires: Cactus.

Wiener, N. (1960). Cibernética. Madrid: Guadiana. 